\title{
Orientational Control of the Physiological Reaction of Cytochrome c Oxidase Tethered to a Gold Electrode
}

\author{
Kenichi Ataka, Björn Richter, and Joachim Heberle*,† \\ Forschungszentrum Jülich, IBI-2: Structural Biology, 52425 Jülich, Germany
}

Received: June 23, 2005; In Final Form: December 21, 2005

\begin{abstract}
The physiological reaction of a membrane protein is reconstituted on a solid-supported electrode by orientational control via the position of an affinity tag. Recombinant cytochrome c oxidase (CcO) from Rhodobacter sphaeroides is immobilized on a chemically modified gold surface via the affinity of a histidine tag (His-tag) to a nickel chelating nitrilotriacetic acid surface. Control of the orientation is achieved by the adsorption of $\mathrm{CcO}$ through the His-tag engineered into the two opposite sites of the membrane protein surface. After reconstitution into a lipid layer, the functionality of this enzyme film electrode is probed by surface-enhanced infrared absorption spectroscopy and cyclic voltammetry. We demonstrate that cytochrome $\mathrm{c}(\mathrm{Cc})$ binds and initiates the catalytic reaction of $\mathrm{CcO}$ only when the latter is orientated with subunit II facing the bulk aqueous phase while $\mathrm{Cc}$ does not interact with the oppositely orientated $\mathrm{CcO}$. We infer from the observed catalytic dioxygen reduction at potentials below $240 \mathrm{mV}$ (vs a normal hydrogen electrode) that reduced Cc mediates electron input into $\mathrm{CcO}$ in a way similar to the physiological pathway. The quantitative analysis of the IR spectra indicates the presence of an inactive population of $\mathrm{Cc}$ bound to $\mathrm{CcO}$ at equal amounts as the redoxactive population. This methodological approach demonstrates that the orientation of the membrane protein can be controlled depending on the position of the affinity tag. The approach is considered to be of general applicability as the introduction of affinity tags is routine in current biochemistry.
\end{abstract}

\section{Introduction}

Membrane proteins play a crucial role in many cellular and physiological processes. Functionally normal membrane proteins are vital to health, and specific defects are associated with many known disease states. Despite the importance of membrane proteins, the knowledge of their mechanisms of action has lagged far behind the knowledge of these properties of proteins in general.

A valuable approach for functional studies of membrane proteins is the use of a solid support that allows control of the properties of the tethered proteins. Integration of redox enzymes with an electrode support and formation of an electrical contact between the electrode and the protein is fundamental. Design of such a bio-functional surface is one of the major issues in contemporary nano-biotechnology. ${ }^{1}$ Key to the design is the immobilization of the proteins under preservation of their native structure and function. ${ }^{2-5}$

Recently, we have devised a system to immobilize a purified protein via the affinity of a genetically introduced histidine tag (His-tag) that selectively binds to a nickel chelating nitrilotriacetic acid (Ni-NTA) self-assembled monolayer (SAM) modified gold surface. ${ }^{6,7}$ Subsequently, the surface-anchored membrane protein is reconstituted in a lipid environment by detergent removal. Each of the surface reconstitution steps has been monitored at the molecular level by surface-enhanced infrared absorption spectroscopy (SEIRAS). ${ }^{8}$ The method establishes a well-controlled model system for the biological cell membrane.

* Author to whom correspondence should be addressed. Phone: +49-(0)521-106-2055. Fax: +49-(0)521-106-2981. E-mail: j.heberle@ fz-juelich.de.

Present address: University of Bielefeld, Biophysical Chemistry (PC III), Universitätsstrasse 25, 33615 Bielefeld, Germany.

10.1021/jp0534131 CCC: \$33.50
Orientational control is particularly relevant in experiments where the vectorial function of the tethered protein is addressed, which is the physiological task of many membrane proteins, e.g., pumps, channels, and transporters.

The present work is focused on functional assaying the reconstituted cytochrome $\mathrm{c}$ oxidase $(\mathrm{CcO})$ film. For the variation of surface orientation, we used recombinant $\mathrm{CcO}$ where the genetically introduced His-tag is situated at opposite sides on the surface of the membrane protein. The natural electron donor cytochrome $\mathrm{c}(\mathrm{Cc})$ can bind to $\mathrm{CcO}$ only when its specific binding site is exposed to the aqueous phase. In the opposite orientation, i.e., when the binding site is facing the electrode surface, the presence of the membrane layer barricades the access of $\mathrm{Cc}$ to the binding site. The metal surface on which the two different constructs have been attached to is not only crucial for surface enhancement but is also used as an electrode to initiate the catalytic reaction and to address the various redox states of the enzyme..$^{9-12}$

Cytochrome c oxidase is the central player in respiration as it binds molecular oxygen and converts it into water. Apart from the protons that are taken up for water formation, protons are also translocated across the membrane to help establish a proton gradient that drives ATP synthesis. The chemical reaction of oxygen splitting requires electrons that are provided by watersoluble Cc. ${ }^{13}$ The delivery of electrons requires Cc to rapidly and specifically dock to the surface of $\mathrm{CcO}$. We used recombinant $\mathrm{CcO}$ from the proteobacterium Rhodobacter sphaeroides for the study of the binding ability with horse heart Cc. Horse heart $\mathrm{Cc}$ has been found to transfer electrons efficiently to $R$. sphaeroides oxidase, and it has been used in most of the kinetic studies. ${ }^{14-17}$

With the two different surface orientations of the membrane protein, we evaluate the binding ability of $\mathrm{Cc}$ and the subsequent 
catalytic activity of $\mathrm{CcO}$ film by cyclic voltammetry and surfaceenhanced infrared difference absorption (SEIDA) spectroscopy. This provides molecular-level insight into the electrostatic structure of the enzyme-substrate complex $(\mathrm{Cc} / \mathrm{CcO})$, the associated electron-transfer reactions, and the dioxygen reduction.

\section{Materials and Methods}

Preparation of the Membrane Reconstituted CcO Film on the Gold Surface. Details of the modification steps of the gold surface to yield a Ni-NTA-terminated thiol self-assembled monolayer have already been described. ${ }^{6}$ Briefly, a thin gold film was prepared on the flat surface of a single reflection silicon (Si) hemicylindrical prism by a chemical deposition technique. Then, the rough surface of the gold film is modified by successive reaction with dithiobis(succinimidylpropionate) (DTSP, Fluka), amino-nitrilotriacetic acid (ANTA, Fluka), and $\mathrm{NiSO}_{4}$ (Sigma) to finally provide a Ni-NTA-terminated surface at which His-tagged proteins can be tethered. Then, the surface was exposed to a solution of $2 \mu \mathrm{M} \mathrm{CcO}$ dissolved in $0.1 \%$ dodecylmaltoside (DM, Anatrace, sol-grade 3105) and $50 \mathrm{mM}$ phosphate buffer ( $\mathrm{pH} 8.0)$. CcO with a $6 \times$ His-tag fused to the carboxy terminus of either subunit I or II was homologously expressed in Rhodobacter sphaeroides and purified according to ref 18 . $\mathrm{CcO}$ adsorbs to the $\mathrm{Ni}-\mathrm{NTA}$ moiety via the coordination of the nitrogen of two imidazole side chains of the $6 \times$ His-tag. After the formation of the $\mathrm{CcO}$ monolayer, excess $\mathrm{CcO}$ is removed by rinsing the surface with buffer.

Incorporation of the membrane protein into the lipid layer is achieved by immersing the surface-adsorbed $\mathrm{CcO}$ layer in a solution of detergent-destabilized lipid vesicles (liposomes) of di-myristoyl-phosphatidyl-choline (DMPC, Sigma). Microporous Bio-Beads (SM2, Bio-Rad) are added to the mixture to remove the detergent, thus creating the lipid-reconstituted $\mathrm{CcO}$ monolayer along the gold surface.

Kinetic FT-IR Spectroscopy To Monitor the Complexation of Cc with CcO. A reference spectrum of the buffer solution ( $75 \mathrm{mM} \mathrm{KCl}, 5 \mathrm{mM}$ phosphate buffer, $\mathrm{pH}=8.0$ ) was recorded with the lipid-reconstituted $\mathrm{CcO}$ monolayer adhered to the gold surface. Subsequently, $4 \mu \mathrm{M} \mathrm{Cc}$ was added to the solution at open-circuit potential, and sample spectra were acquired at a resolution of $4 \mathrm{~cm}^{-1}$. The first 15 spectra were recorded each for $10 \mathrm{~s}$. The subsequent series of 15 spectra have been taken at an interval of 60 and $300 \mathrm{~s}$, respectively.

Spectroelectrochemistry and Surface-Enhanced FT-IR Difference Spectroscopy. The gold thin film is used as a working electrode. It is connected via to a copper plate a potentiostat (Autolab PGSTAT 12, Metrohm, Filderstadt, Germany) that controls and determines the electrochemical response of the $\mathrm{CcO}$-modified surface by cyclic voltammetry. $\mathrm{Ag} / \mathrm{AgCl} / 3$ $\mathrm{M} \mathrm{KCl}$ and $\mathrm{Pt}$ mesh were used as a reference and a counter electrode, respectively. All potentials given refer to the normal hydrogen electrode, $\mathrm{NHE}\left(+0.212 \mathrm{~V}\right.$ vs $\mathrm{Ag} / \mathrm{AgCl}$ in $\left.20^{\circ} \mathrm{C}\right)$. A single-beam background IR spectrum was taken at $0.11 \mathrm{~V}$ vs NHE. Then, the potential was continuously increased (sweep rate of $2 \mathrm{mV} \mathrm{sec}-1$ ), and sample spectra were acquired. Typically, 200 scans were coadded to reduce the noise. The spectral acquisition time took $10 \mathrm{~s}$; thus each spectrum represents the integration over a potential range of $20 \mathrm{mV}$. Experiments have been performed on several samples, which were averaged at the corresponding potentials until a sufficient signal-to-noise ratio was achieved.

\section{Results}

The strategy of this study is schematically depicted in Figure 1. Two types of recombinant $\mathrm{CcO}$, which carry the His-tag on
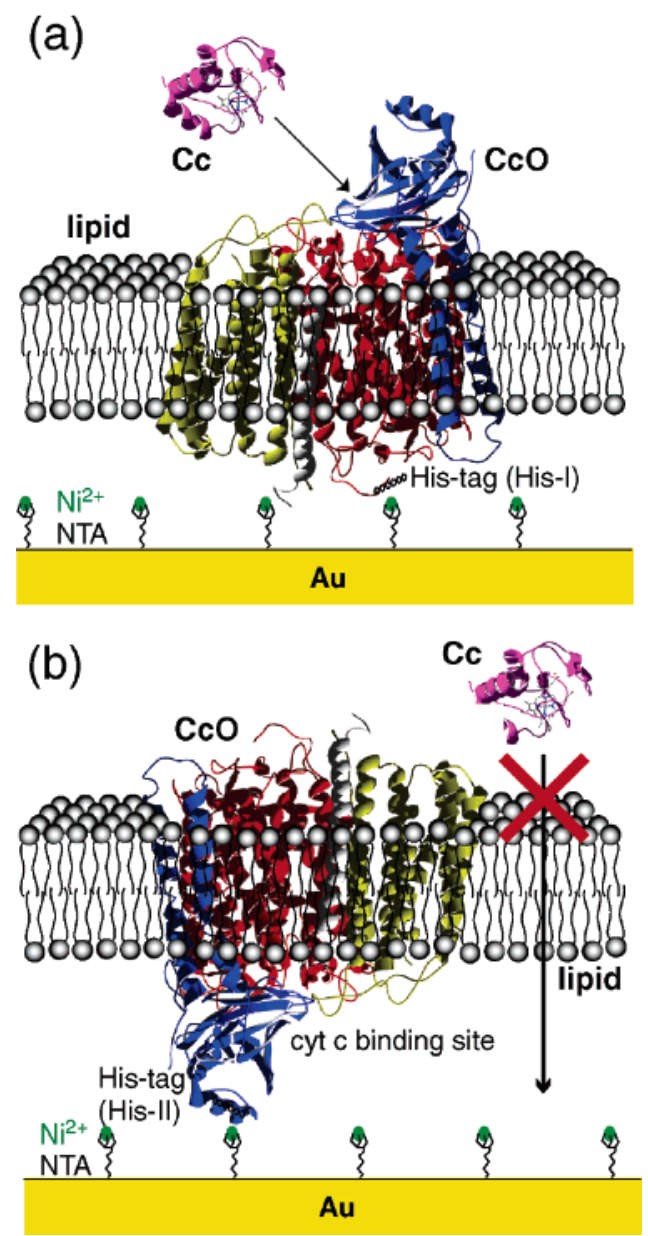

Figure 1. Conceptual design to produce a solid-supported monolayer of an orientated membrane protein embedded in the lipid bilayer (DMPC). (a) Cytochrome c oxidase (CcO) is adsorbed to the Ni-NTAterminated SAM layer via the His-tag (His-I) positioned at the C-terminus of subunit I (red ribbons). The binding site for the natural electron donor cytochrome c $(\mathrm{Cc}$, purple) is exposed toward the electrolyte solution. (b) Cytochrome c oxidase $(\mathrm{CcO})$ is oppositely orientated by positioning the His-tag (His-II) at the C-terminus of subunit II (blue ribbons). In this orientation, Cc cannot reach the binding site at $\mathrm{CcO}$ because of the presence of the lipid bilayer (crossed arrow).

different subunits, have been expressed and purified. One of the constructs of $\mathrm{CcO}$ carries the His-tag at the $\mathrm{C}$-terminus of subunit I (His-I) where the hydrophilic residues are exposed toward the cytoplasmic side of the cell. The other construct has the His-tag on the C-terminus of subunit II (His-II) where the hydrophilic residues are exposed to the periplasm. The periplasmatic extension of subunit II harbors the docking site for Cc, which comprises an agglomeration of acidic residues. ${ }^{14,17}$ Since the His-tag binds specifically to the Ni-NTA-modified gold surface, the His-I construct provides $\mathrm{CcO}$ with the orientation where the cytoplasm side faces the gold surface; i.e., the $\mathrm{Cc}$ binding site is exposed to the bulk solution (Figure 1a). The His-II construct binds to the Ni-NTA surface to orient $\mathrm{CcO}$ with the periplasmic side toward the gold surface (Figure 1b). In this orientation, the binding site is not accessible to $\mathrm{Cc}$ due to the barricade imposed by the lipid bilayer.

CcO Adsorption on the Ni-NTA-Modified Gold Electrode. The gold surface has been modified by several steps to generate a Ni-NTA-terminated self-assembled monolayer (SAM). $\mathrm{CcO}$ is added to the electrolyte solution and binds with high affinity to the chemically modified electrode (CME) via the His-tag that has been genetically engineered into the polypeptide sequence. Figure 2 shows the SEIRA spectra of 


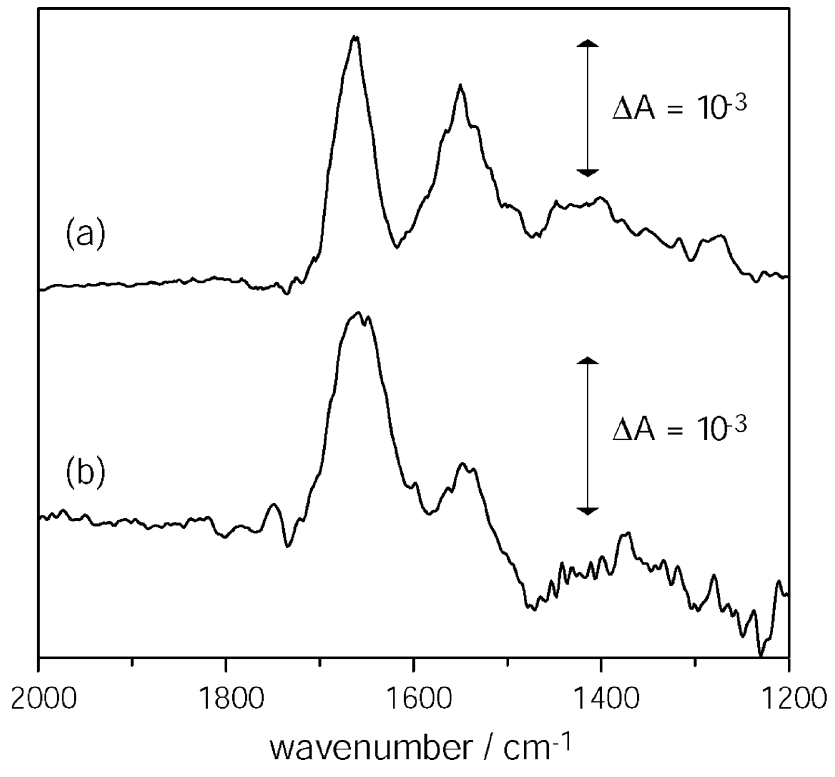

Figure 2. Surface-enhanced infrared absorption (SEIRA) spectra of detergent-solubilized cytochrome c oxidase adsorbed to the Ni-NTAmodified gold surface through the His-tag on (a) subunit I (His-I orientation, see Figure 1a) and (b) subunit II (His-II orientation, see Figure 1b).

$\mathrm{CcO}$ after adsorption to the Ni-NTA SAM via the His-tag on subunit I (His-I in part a) or via the His-tag on subunit II (HisII in part b). Through the use of constructs with the His-tag on opposite sides, the orientation of the protein is reversed with respect to the gold surface. The recorded IR spectra show the same features with the prominent amide bands to absorb at 1658 $\mathrm{cm}^{-1}$ (amide $\mathrm{I}$, predominantly $\mathrm{C}=\mathrm{O}$ stretching vibration of the peptide bond) and at $1544 \mathrm{~cm}^{-1}$ (amide II, $\mathrm{C}=\mathrm{N}$ stretch coupled to $\mathrm{N}-\mathrm{H}$ bending vibration), ${ }^{19}$ irrespective of surface orientation. The intensities of these bands are also comparable, which suggests that the surface coverage of the two $\mathrm{CcO}$ constructs (His-I and His-II) is almost identical despite the difference in their functionality (vide infra). It is expected from the short range of the surface-enhancement effect (decay lengths in the range of $5 \mathrm{~nm}^{20}$ ) that the opposite orientation of the two proteins may lead to deviations in their IR spectrum. However, the current signal-to-noise ratio does not allow for such a quantitative analysis.

Orientational Effect on Cc Binding to $\mathrm{CcO} . \mathrm{Cc}$ is the natural electron donor to $\mathrm{CcO}$ in mitochondrial respiration. $\mathrm{Cc}$ binds to a specific site at subunit II of $\mathrm{CcO}$, which is geometrically as well as electrostatically optimized for binding and electron transfer. To mimic the physiological process, the surface-bound $\mathrm{CcO}$ was reconstituted into a lipid bilayer, and $\mathrm{Cc}$ was added to the electrolyte solution. Figure 3 a shows the recorded IR spectra during the adsorption of $\mathrm{Cc}$ to $\mathrm{CcO}$ orientated with the $\mathrm{Cc}$ binding site toward the electrolyte solution (His-I). Two prominent peaks appear at 1658 and 1550 $\mathrm{cm}^{-1}$ due to the amide I and the amide II modes of Cc, respectively. The spectra correspond well to the absolute spectrum of $\mathrm{Cc}$ when dissolved in the aqueous bulk phase or when adsorbed to a chemically modified surface. ${ }^{6}$ The gradual increase in intensity provides direct evidence for adsorption of $\mathrm{Cc}$ to the reconstituted $\mathrm{CcO}$.

The binding experiment has been repeated under identical conditions albeit with $\mathrm{CcO}$ oppositely orientated, i.e., the $\mathrm{Cc}$ binding site being sequestered from the bulk electrolyte. Contrary to the former observation, amide bands from adsorbed $\mathrm{Cc}$ are hardly observed even after $30 \mathrm{~min}$ of incubation of the
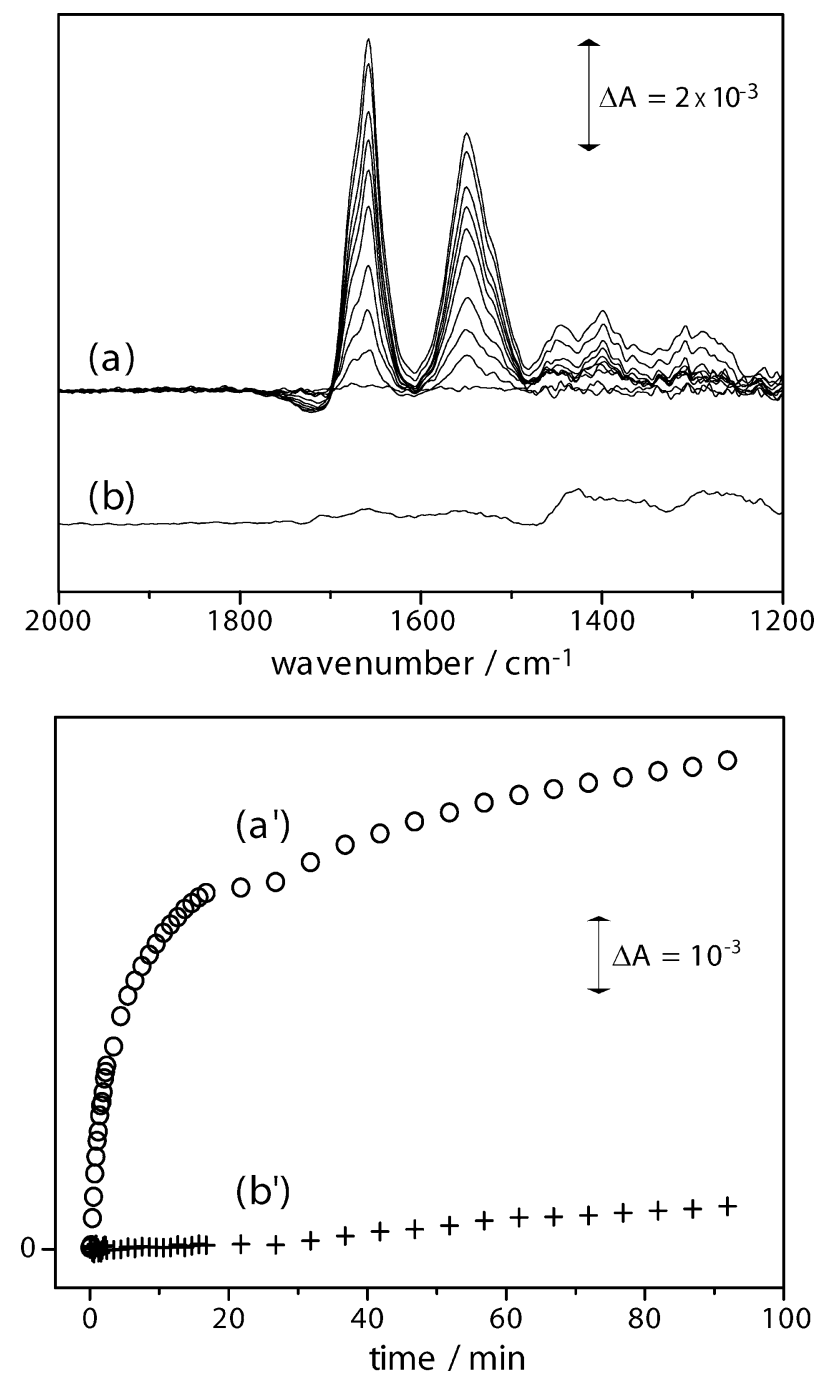

Figure 3. SEIRA spectra (a in the top panel) of cytochrome c (Cc) bound to the solid-supported monolayer of cytochrome c oxidase $(\mathrm{CcO})$. $\mathrm{CcO}$ is orientated with the $\mathrm{Cc}$ binding pocket facing the aqueous bulk solution (His-I orientation, see Figure 1a). Spectra are taken at $10 \mathrm{~s}$, $30 \mathrm{~s}, 1 \mathrm{~min}, 2 \mathrm{~min}, 5 \mathrm{~min}, 10 \mathrm{~min}, 15 \mathrm{~min}, 30 \mathrm{~min}, 60 \mathrm{~min}$, and 90 min after addition of $4 \mu \mathrm{M}$ Cc. The spectrum of the cytochrome c oxidase monolayer has been taken as a reference. Trace $\mathrm{b}$ corresponds to the SEIRA spectrum taken after $30 \mathrm{~min}$ of incubation of $4 \mu \mathrm{M} \mathrm{Cc}$ with the reconstituted cytochrome $\mathrm{c}$ oxidase monolayer whose $\mathrm{Cc}$ binding pocket faces the electrode surface (His-II orientation, see Figure $1 b)$. The bottom panel corresponds to the derived adsorption kinetics of Cc to cytochrome $\mathrm{c}$ oxidase in the His-I orientation $\left(\mathrm{a}^{\prime}\right)$ or in the His-II orientation ( $\mathrm{b}^{\prime}$ ). The intensity at $1658 \mathrm{~cm}^{-1}$ (amide I band in the top panel) is plotted versus the adsorption time.

bilayer-reconstituted $\mathrm{CcO}$ (Figure $3 \mathrm{~b}$ ). This suggests that $\mathrm{Cc}$ does not significantly adsorb to $\mathrm{CcO}$ when the binding site is orientated toward the solid surface. Minor spectral contributions may be caused by the adsorption of $\mathrm{Cc}$ to the lipid headgroups or to the Ni-NTA surface through defects of the lipid bilayer. Nevertheless, it is apparent from these results that Cc binds to the reconstituted $\mathrm{CcO}$ only at a proper orientation of the latter. Surprisingly, unspecific binding of $\mathrm{Cc}$ to the lipid surface (DMPC) is negligible.

The kinetics of adsorption have been determined from the evolution of the amide I band in the binding experiment and plotted versus incubation time (bottom panel in Figure 3) for the two oppositely orientated $\mathrm{CcO}$ constructs ( $\mathrm{a}^{\prime}$ for His-I and $\mathrm{b}^{\prime}$ for His-II). Although adsorption of $\mathrm{Cc}$ is obvious when $\mathrm{CcO}$ is orientated with the binding site facing the bulk solution, the 

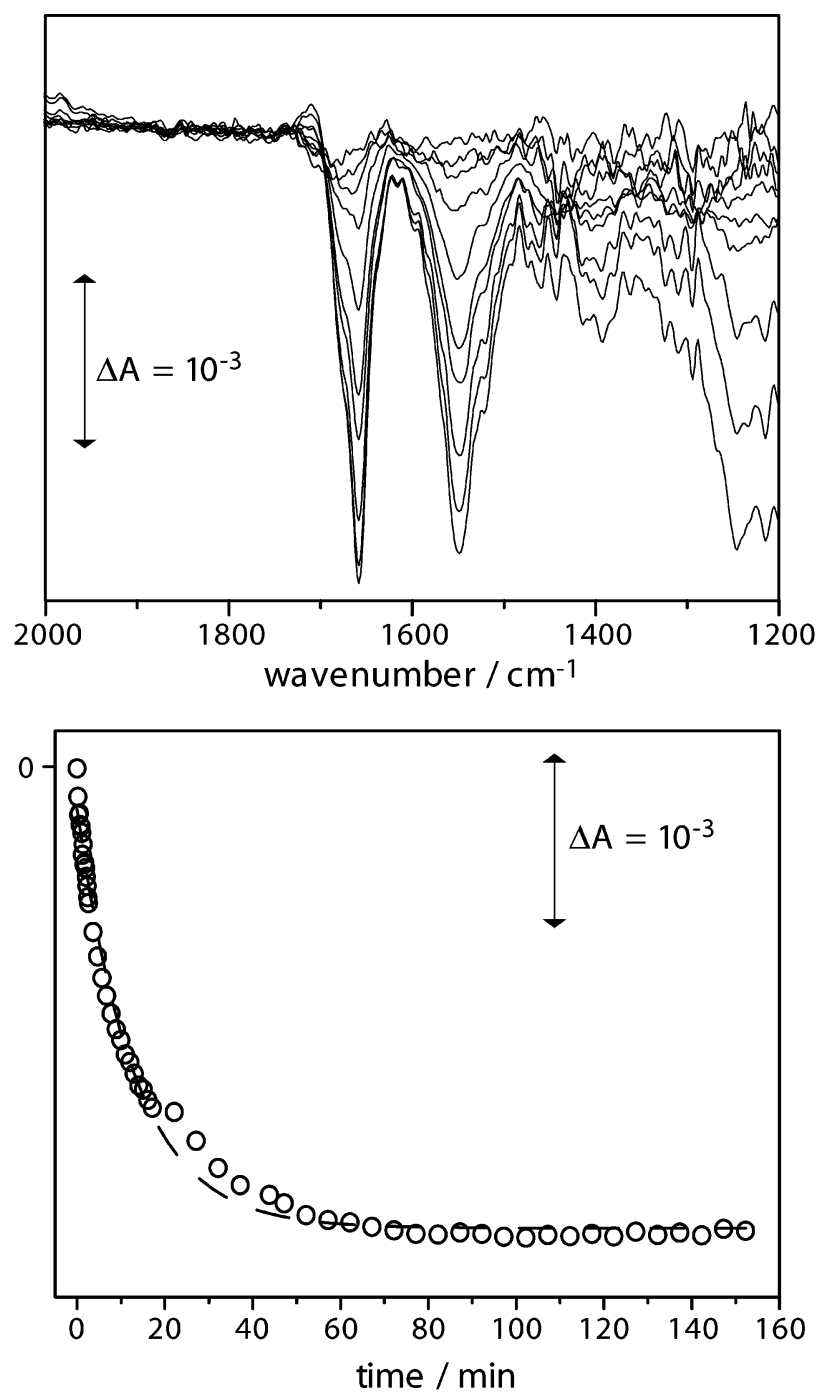

Figure 4. Surface-enhanced infrared difference absorption (SEIDA) spectra of the desorption process of cytochrome $\mathrm{c}$ from the cytochrome c oxidase monolayer (top) and the corresponding desorption kinetics (bottom). Desorption is induced by increasing the electrolyte concentration from 75 to $300 \mathrm{mM} \mathrm{KCl}$. Difference spectra have been taken at $10 \mathrm{~s}, 30 \mathrm{~s}, 1 \mathrm{~min}, 2 \mathrm{~min}, 5 \mathrm{~min}, 10 \mathrm{~min}, 30 \mathrm{~min}, 60 \mathrm{~min}$, and 90 min after induction. For kinetic analysis, the intensity of the band at $1658 \mathrm{~cm}^{-1}$ (amide I vibration) is plotted versus the desorption time. The dashed line is the best fit of a monoexponential decay. The corresponding rate constant of desorption is determined to $k_{\mathrm{des}}=1.3$ $\times 10^{-3} \mathrm{~s}^{-1}$.

adsorption kinetics is not simple. In the initial phase of adsorption $(<20 \mathrm{~min})$, the adsorption kinetics is monotonic and obeys an exponential increase. It reaches a plateau after about 30 min followed by an additional increase in coverage of $\mathrm{Cc}$. This kinetic behavior has not been observed in the case of $\mathrm{Cc}$ adsorption to a carboxy-terminated alkane thiol surface that exhibits a monotonic increase throughout the adsorption kinetics. ${ }^{6}$

It is well-known that the oxidation reaction of $\mathrm{Cc}$ by $\mathrm{CcO}$ depends on ionic strength. ${ }^{14,15,21}$ The activity reaches a maximum at $75 \mathrm{mM} \mathrm{KCl}$ and decreases as the ionic strength increases due to dissociation of $\mathrm{Cc}$ from $\mathrm{CcO} .{ }^{14}$ At $300 \mathrm{mM} \mathrm{KCl}$, the activity is close to zero, suggesting the complete dissociation of the active Cc. ${ }^{15}$ As a control for Cc binding to the active site of $\mathrm{CcO}, \mathrm{Cc}$ was desorbed by increasing the ionic strength. The top panel in Figure 4 shows the IR difference spectra after the $\mathrm{KCl}$ concentration was increased from 75 to $300 \mathrm{mM}$. The disappearance of the amide bands indicates the salt-induced

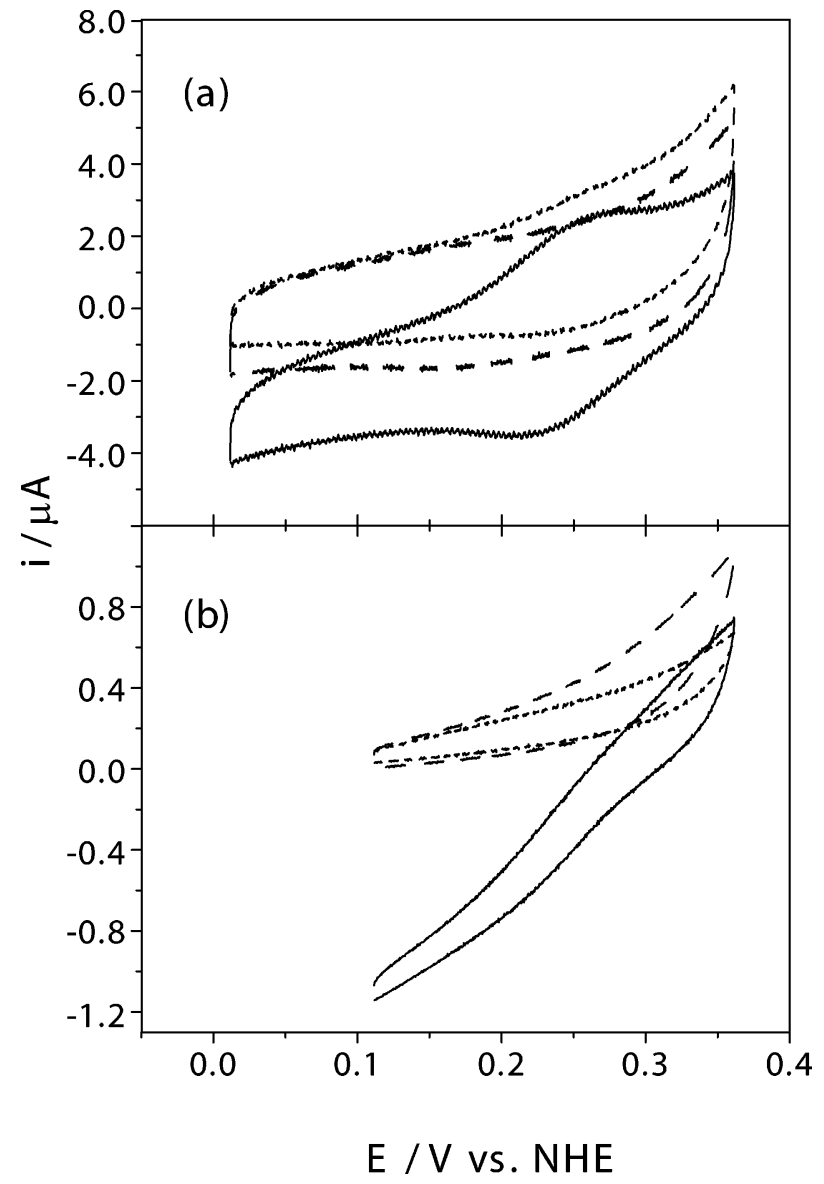

Figure 5. Cyclic voltammograms (CVs) of the cytochrome c oxidase modified electrode recorded with scan rates of (a) $50 \mathrm{mV} \mathrm{s}^{-1}$ and (b) $2 \mathrm{mV} \mathrm{s}^{-1}$. The solid traces correspond to the CV of surface-attached cytochrome $\mathrm{c}$ oxidase in the His-I orientation in the presence of cytochrome $\mathrm{c}$. The dashed lines are $\mathrm{CV}$ traces from identical experiments but in the absence of the natural reductant cytochrome $\mathrm{c}$. The dotted traces are from experiments on cytochrome c oxidase in the His-II orientation in the presence of cytochrome $\mathrm{c}$.

dissociation of $\mathrm{Cc}$ from $\mathrm{CcO}$. The desorption proceeds rather sluggishly and monotonically (bottom panel in Figure 4). It takes $\sim 80$ min to reach steady-state desorption. Importantly, less than half of the $\mathrm{Cc}$ molecules are desorbed by this procedure as discerned from the limiting differential absorbance of -0.003 (compare to $A=+0.007$ for the binding isotherm, a' in Figure $3)$. This suggests that the binding constant has not moved far enough for full dissociation of $\mathrm{Cc}$ even at $300 \mathrm{mM}$ salt concentration. Nevertheless, reduction of $\mathrm{CcO}$ from those $\mathrm{Cc}$ that remain on the surface is not observed. Thus, we conclude that the remaining $\mathrm{Cc}$ is inactive in terms of electron transfer to $\mathrm{CcO}$. It is evident from the experiments on $\mathrm{CcO}$ with the $\mathrm{Cc}$ binding site occluded from the bulk solution (His-II orientation, trace $\mathrm{b}$ of Figure 3) that $\mathrm{Cc}$ does not bind to the lipid layer. Therefore, a second, albeit nonfunctional, binding site for $\mathrm{Cc}$ has to be assumed on the surface of $\mathrm{CcO}$.

Functionality of the $\mathrm{Cc}-\mathrm{CcO}$ Complex. After $\mathrm{Cc}$ binds to $\mathrm{CcO}$, the functionality of the $\mathrm{Cc}-\mathrm{CcO}$ complex is studied by cyclic voltammetry in the presence of atmospheric $\mathrm{O}_{2}$. The electrochemical response of the two proteins can be selected by the sweep rate in cyclic voltammetry. At a fast sweep rate of $50 \mathrm{mV} / \mathrm{s}$ (Figure $5 \mathrm{a}$ ), the response of $\mathrm{Cc}$ is monitored when it is redox-active (continuous trace). A midpoint potential of $+244 \mathrm{mV}$ can be derived from the maximum and minimum of the redox current. A response of $\mathrm{CcO}$ is not detectable under these conditions because the turnover rate is too slow. Remark- 
ably, however, the $\mathrm{Cc} / \mathrm{CcO}$ film displays substantial catalytic activity at a low scan rate to allow for multiple turnovers. As the potential sweeps at a rate of $2 \mathrm{mV} \mathrm{s}^{-1}$ (continuous trace in Figure 5b), a drastic increase in the reduction current is observed at potentials below $+260 \mathrm{mV}$. This voltammetric behavior is the catalytic wave characteristic of dioxygen reduction. The inflection point of the wave corresponds to the formal potential of $\mathrm{Cc}$ measured under the faster scan rate (continuous trace in Figure 5a). This indicates that the electrons from the electrode are transferred via $\mathrm{Cc}$ as a redox mediator to reach the catalytic center of $\mathrm{CcO}$. The catalytic current has also been observed by Haas et al. ${ }^{10}$ using a different attachment strategy.

With the addition of $\mathrm{Cc}$ to $\mathrm{CcO}$ tethered to the electrode where the binding site is inaccessible, the cyclic voltammogram does not display any significant current, irrespective of the sweep rate (dashed traces in Figure 5). This electrochemical observation is in line with the FT-IR spectroscopic result (Figure 3, trace b), which showed that $\mathrm{Cc}$ does not adsorb at this orientation of $\mathrm{CcO}$ (His-II) to the film electrode.

In the absence of the natural electron donor $\mathrm{Cc}, \mathrm{CcO}$ does not exhibit any electroactivity at all, irrespective of the orientation (dotted traces in Figure 5). This suggests that there is no direct electrical communication with the gold electrode under our conditions.

From the charge flow of the redox wave in the cyclic voltammogram, the number of $\mathrm{Cc}$ molecules can be calculated that undergo electron transfer from the electrode. The redox charge was determined by subtraction of the double-layer charging current in the absence of $\mathrm{Cc}$ in the solution (dashed trace in Figure 5a) from the presence of $\mathrm{Cc}$ (solid trace in Figure 5a). Through the use of the roughness factor of $2.5,{ }^{22}$ the surface coverage of electroactive $\mathrm{Cc}$ is determined to be $4.9 \mathrm{pmol} \mathrm{cm}{ }^{-2}$. This value corresponds very well to the coverage of a densely

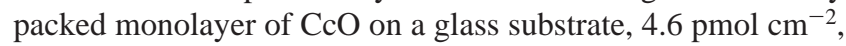
prepared by the Langmuir-Blodgett technique. ${ }^{10}$ It is also very

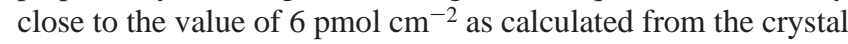

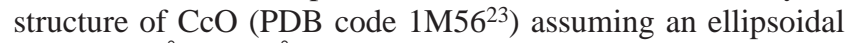
disk of $45 \AA \times 70 \AA$ for the in-plane dimension of $\mathrm{CcO}$ from $R$. sphaeroides. This result implies that the observed redox current of $\mathrm{Cc}$ is mainly carried by those adsorbed to the active site of $\mathrm{CcO}$, which forms a densely packed monolayer on the gold surface. Such a densely packed monolayer has been observed by atomic force microscopy for reconstituted $\mathrm{CcO}$ adhered to a Ni-NTA/Au(111) single-crystal surface. ${ }^{24}$

Potential-Induced Difference Spectra of the $\mathrm{Cc} / \mathrm{CcO}$ Complex Film. Electrochemically induced IR difference spectroscopy has been performed on the functional $\mathrm{Cc} / \mathrm{CcO}$ complex (Figure 6, continuous traces). The IR spectra have been recorded simultaneously with the cyclic voltammogram (Figure 5b). As the potential is increased, several sharp bands appear. The negative peaks at $1692,1643,1626$, and $1514 \mathrm{~cm}^{-1}$ correspond to the reduced state, and the positive peaks at $1676,1636,1557$, 1518 , and $1506 \mathrm{~cm}^{-1}$ to the oxidized state of the complex. These peak positions correspond very well to the redox-induced difference spectra of $\mathrm{Cc}$ in the solution phase or when adsorbed to a CME. ${ }^{25}$ Thus, these bands emanate from the conformational changes of $\mathrm{Cc}$ induced by electrochemical oxidation when adsorbed to the $\mathrm{CcO}$ surface. The detailed assignment of these bands to molecular vibrations of Cc have already been published. ${ }^{25}$ Briefly, the negative and positive pair at 1692/1676 $\mathrm{cm}^{-1}$ is assigned to an amide I mode of a type III $\beta$-turn structure of the amino acids 14-19 and/or 67-70 of the polypeptide. The $1636 / 1626 \mathrm{~cm}^{-1}$ pair is assigned to the extended $\beta$-turn structure comprising residues $37-40$ and/or

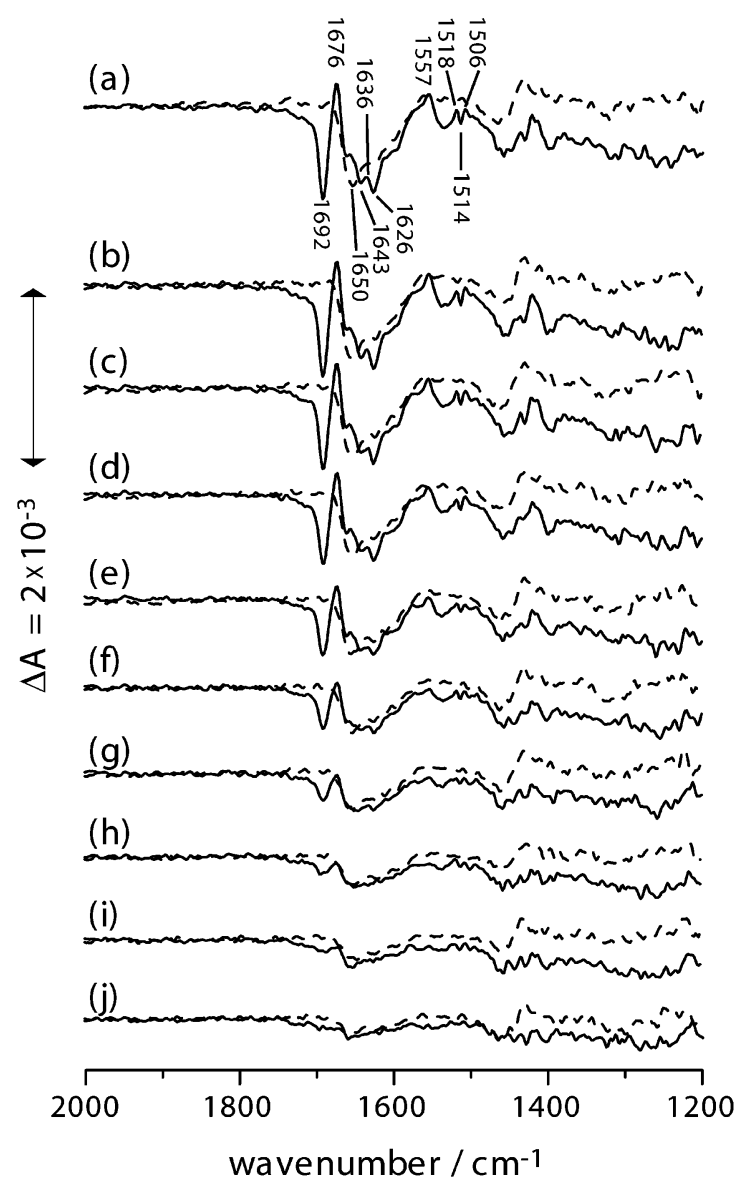

Figure 6. Set of potential-induced surface-enhanced IR difference absorption (SEIDA) spectra of the cytochrome c/cytochrome c oxidase monolayer adhered to the Ni-NTA-modified gold electrode. Spectra have been recorded at oxidizing potentials of (a) +0.36 , (b) +0.34 , (c) +0.32 , (d) +0.29, (e) +0.27 , (f) +0.25 , (g) +0.23 , (h) +0.21 , (i) +0.18 , and (j) $+0.16 \mathrm{~V}$ (solid traces) with a reference spectrum of the reduced state taken at $+0.11 \mathrm{~V}$. The dashed traces represent the IR difference spectra of the cytochrome $\mathrm{c}$ oxidase in the absence of cytochrome $\mathrm{c}$.

$57-79$. The band at $1557 \mathrm{~cm}^{-1}$ is due to an amide II mode while the bands at $1518 / 1514 / 1506 \mathrm{~cm}^{-1}$ are assigned to different in-plane ring vibrations of tyrosine (Tyr48 and/or Tyr67). Besides of these sharp bands, a broad negative band centered at around $1650 \mathrm{~cm}^{-1}$, appears as the potential increases. This broad feature does not originate from Cc but from the $\mathrm{Ni}-\mathrm{NTA}$ underlayer. This is evident from control experiments performed in the absence of Cc (dashed traces in Figure 6) and from experiments on the pure $\mathrm{Ni}-\mathrm{NTA}$ layer (Figure $\mathrm{S} 1$ in the Supporting Information). The appearance of bands from the Ni-NTA SAM may due to the potential-induced reorientation or Stark tuning effect. ${ }^{26}$ Since the Ni-NTA SAM is close to the metal surface, it is prone to be affected by the change in the electromagnetic field tuned by the potential (vibrational Stark effect). Moreover, the intensity of the broad band shows a potential dependence $(+$ in Figure 7$)$ much different from the potential dependence of $\mathrm{Cc}(\mathrm{O}$ in Figure 7). The latter corresponds very well to the charge flown during the redox reaction of $\mathrm{Cc}$ (continuous trace in Figure 7). The increase in peak height at $1644 \mathrm{~cm}^{-1}$ is rather proportional to the potential increase and does not fit to the charge profile of Cc. These results demonstrate that the discussed IR bands must be of different molecular origin, indeed.

After the assignment of the broad background absorption change to the Ni-NTA layer (dashed spectrum in Figure 6), it is subtracted from the redox-induced IR difference spectrum 


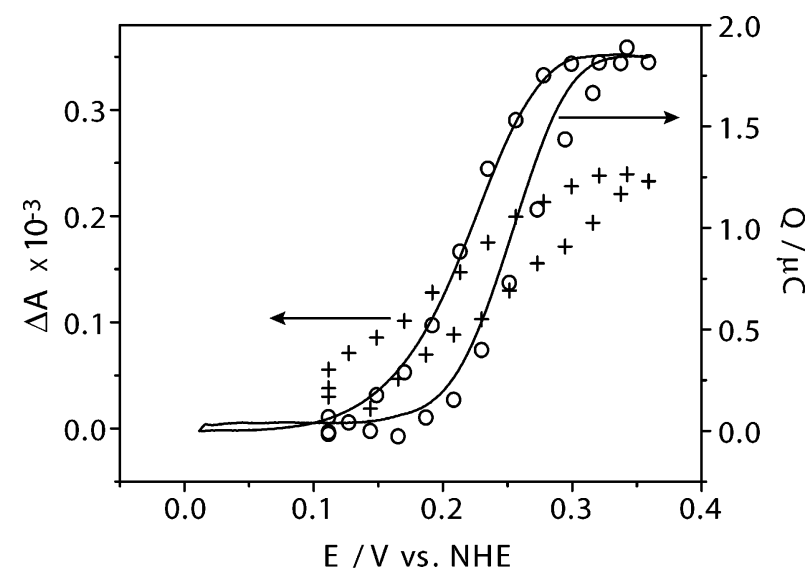

Figure 7. Plot of the intensities of selected IR difference bands (left ordinate) versus the applied redox potential. Circle $(O)$ : Intensity difference between the bands at 1692 and $1676 \mathrm{~cm}^{-1}$. Cross (+): Intensity of the band at $1644 \mathrm{~cm}^{-1}$. The continuous trace represents the charge flow (right ordinate) derived from the integration of the redox current of Cc (solid trace in Figure 5a).

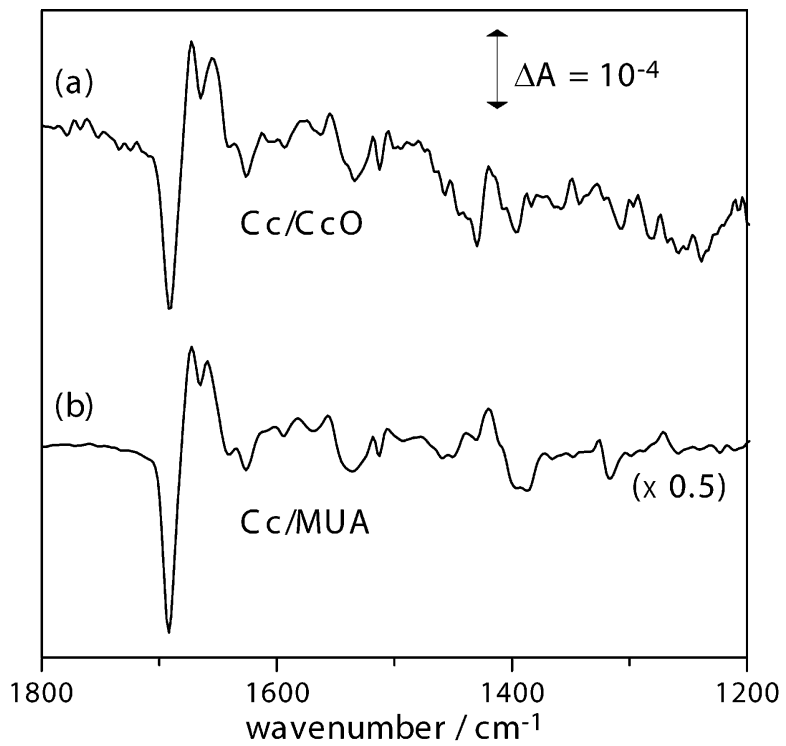

Figure 8. (a) SEIDA spectrum of cytochrome $\mathrm{c}$ when adsorbed to cytochrome c oxidase $(\mathrm{Cc} / \mathrm{CcO})$. The spectrum has been calculated by subtracting the redox difference of $\mathrm{CcO}$ bound to the Ni-NTA SAM (dashed trace in Figure 6a) from the difference spectrum of Cc bound to the solid-supported film of $\mathrm{CcO}$ (continuous trace in Figure 6a). (b) Potential-induced redox difference spectrum of cytochrome $\mathrm{c}$ when adsorbed to the mercaptoundecanoic-acid-modified $\mathrm{Au}$ electrode (Cc/MUA).

(continuous spectrum in Figure 6) to yield the pure vibrational response of the $\mathrm{Cc} / \mathrm{CcO}$ complex to oxidation (Figure 8a). This double difference is remarkably similar to the potential-induced difference spectrum of $\mathrm{Cc}$ adsorbed on a carboxy-terminated SAM (mercaptoundecanoic acid, Figure 8b). It is noted that the difference spectra of $\mathrm{Cc}$ when adsorbed to SAMs with terminal groups of different chemical functionality (hydoxyl, zwitterionic, or pyridine) exhibit completely different relative intensities (see ref 25 for the spectra). Thus, it is concluded that the carboxyterminated surface of the thioalkane mimics the (physiological) $\mathrm{Cc}$ binding site of $\mathrm{CcO}$, which is dominated by negatively charged amino acid side chains (Asp and Glu, see Discussion).

\section{Discussion}

Assessment of the Reconstituted Membrane Protein Monolayer Electrode. We have succeeded to construct a functional membrane protein monolayer electrode that provides distinct advantages as compared to those reported earlier. ${ }^{9-11,27,28}$ First, the orientation of adsorbed $\mathrm{CcO}$ is freely controlled by exploiting the binding ability of the His-tag to the preformed $\mathrm{Ni}-\mathrm{NTA}$ layer along the gold surface.

Hawkridge and co-workers ${ }^{9,11,29}$ have also constructed anisotropically orientated $\mathrm{CcO}$ films. Solubilized $\mathrm{CcO}$ was detergentdialyzed against a mixture of dioleoyl phosphatidylethanolamine (DOPE) and dioleoyl phosphatidylcholine (DOPC) to form a protein/lipid layer on a silver-deposited gold electrode that was partially modified with an alkanethiol (octadecylmercaptan). The orientation of the adsorbed $\mathrm{CcO}$ was driven by the hydrophobic interaction of the enzyme and the SAM layer. However, it is not trivial with this method to change the orientation of $\mathrm{CcO}$. Also, the application of the methodology to other proteins is difficult due to their different structural and chemical nature. In our method, the surface orientation of the enzyme is conveniently controlled by inserting the His-tag into virtually any position of the protein by molecular genetic means. Moreover, the methodology allows the adherence of any protein that is amenable to recombinant techniques. Therefore, the Ni-NTAmodified electrode represents a versatile and general nanotechnological approach.

The functionality of the $\mathrm{CcO}$ layer is demonstrated by recording a catalytic reduction current in the negative potential region. We conclude from the fact that this current is observed only when $\mathrm{Cc}$ is bound at the dedicated site of $\mathrm{CcO}$ (Figure $5 b)$ the electrons enter $\mathrm{CcO}$ via the physiological pathway. This finding is corroborated by the observation that the catalytic wave starts to appear as soon as $\mathrm{Cc}$ is reduced. These results are consistent with those reported by Haas et al. ${ }^{10}$ who used a detergent-solubilized $\mathrm{Cc}-\mathrm{CcO}$ complex physisorbed to a 3-mercapto-1-propanol SAM.

Taking into account the considerable electron-transfer distance from the electrode to $\mathrm{Cc}$ when adsorbed to $\mathrm{CcO}$ (Figure 1a), "through-space" electron transfer is hardly conceivable. Nevertheless, cyclic voltammetry (solid trace in Figure 5a) clearly demonstrates electron transfer to $\mathrm{Cc}$. Contact of $\mathrm{Cc}$ with the electrode followed by diffusion to the $\mathrm{CcO}$ binding is excluded by the fact that $\mathrm{Cc}$ is unable to penetrate the lipid bilayer. This is demonstrated by the SEIRAS experiment (Figure 3b) where no adsorption of $\mathrm{Cc}$ is detected when $\mathrm{CcO}$ is in the His-II orientation (Figure 1b). It may be concluded from these experimental results that $\mathrm{CcO}$ acts as a mediator that facilitates electron transfer from the electrode to the distant $\mathrm{Cc}$ via a "through-bond" mechanism.

The monolayer of the $\mathrm{Cc}-\mathrm{CcO}$ complex displays catalytic activity only at low sweep rates that allow for multiple turnovers. Catalytic activity comprises all of the molecular reactions that finally lead to dioxygen reduction including electron transfer from $\mathrm{Cc}$ to $\mathrm{CcO}$, electron transfer among the various redox centers within $\mathrm{CcO}$, proton uptake for water production, proton translocation across the whole protein, and diffusion of oxygen to the active site. The rate of the limiting reaction determines the catalytic activity. If the potential sweep rate is faster than the rate-limiting reaction of $\mathrm{CcO}$, then the catalytic current is not observable, but $\mathrm{Cc}$ is reduced by the solid electrode.

Several studies have reported on the direct electric coupling between $\mathrm{CcO}$ and the electrode. ${ }^{9-11,27,28}$ However, the associated catalytic oxygen reduction has been scarcely reported. The experiment with $\mathrm{CcO}$ orientated with the $\mathrm{Cc}$ binding facing the bulk aqueous solution (His-I) did not show any detectable redox contact between electrode and protein. This implies that the distances between the oxidase redox cofactors are too far away 
from the electrode to promote significant electron-transfer rates. Alternatively, the $\mathrm{CcO}$ is not properly orientated in this configuration. If the His-tag is put on subunit $\mathrm{II}$, then $\mathrm{CcO}$ is adsorbed such that the electron entering site to $\mathrm{Cu}_{\mathrm{A}}$ is close to the electrode surface $(\sim 50 \AA) .{ }^{30}$ Nevertheless, we could not detect any current (dotted trace in Figure 5) induced by direct electron transfer to $\mathrm{CcO}$ under the applied conditions. Our experiments were performed in the potential region below $360 \mathrm{mV}$ to avoid contributions from the redox reaction of $\mathrm{Ni}^{2+} / \mathrm{Ni}^{3+}\left(E_{\text {ox }}=\sim 0.5 \mathrm{~V}, E_{\text {red }}=\sim 0.35 \mathrm{~V}\right.$ vs NHE) for the Ni-NTA SAM (data now shown). However, this potential region overlaps with the potential of the heme $\mathrm{a}_{3}$ redox site $(350 \mathrm{mV}),{ }^{9,31}$ which has been reported for direct electron transfer between $\mathrm{CcO}$ and the electrode. Thus, it is rather difficult to disentangle these two contributions by cyclic voltammetry. It is also not easily distinguished from IR signals of the Ni-NTA layer, which appears around $1600 \mathrm{~cm}^{-1}$.

Structural Aspects of the Cytochrome c/Cytochrome c Oxidase Complex as Determined by SEIDAS. The binding of $\mathrm{Cc}$ and electron delivery to its cognate oxidase comprise specific structural and electronic premises. The redox-induced SEIDA spectrum of $\mathrm{Cc}$ when bound to $\mathrm{CcO}$ has been recorded (Figure 8a). The comparison with the SEIDA spectrum of Cc electrostatically attached to a SAM of the carboxy-terminated alkanethiol mercaptoundecanoic acid MUA (Figure 8b) reveals great similarity between the two spectra. We have shown in a recent publication ${ }^{25}$ that the amplitude of the SEIDA bands of $\mathrm{Cc}$ is critically sensitive toward the chemical nature of the SAM surface. Only a carboxy-terminated SAM surface shows a spectrum like in Figure $8 \mathrm{~b}$ whereas SAMs with other terminal groups (hydroxy, pyridine, or amino carboxylic acid) exhibit distinctly different SEIDA spectra. Therefore, it can be inferred that the physiological docking site of Cc comprises a preponderance of carboxylate residues, i.e., those of the side chains of aspartates or glutamates. Indeed, Ferguson-Miller et al. ${ }^{14}$ have identified residues Glu148, Glu157, Asp195, Asp214, and Trp143 (all in subunit II of CcO from $R$. sphaeroides) as the major interaction partners for horse heart Cc. This model is supported by kinetic experiments ${ }^{16}$ and by computational analysis. ${ }^{32}$ The conservation of these residues among CcOs from various organisms ${ }^{17,33-35}$ points to their relevance in this respect. These residues of $\mathrm{CcO}$ interact with the terminal ammonium group of lysines at positions $8,13,27,72$, and 86/87 of horse heart Cc. ${ }^{36-38}$ The similarity in the SEIDA spectra also demonstrates that a carboxy-terminated surface represents a viable model system for binding studies of $\mathrm{Cc}$.

Despite the qualitative similarity in the potential-induced IR difference spectra of $\mathrm{Cc}$ on MUA and $\mathrm{CcO}$, several distinctive differences are apparent in their adsorption behavior. First, the IR absorption bands of $\mathrm{Cc}$ when adsorbed to $\mathrm{CcO}$ are unexpectedly strong as compared to the amount that is involved in electron transfer as derived from the redox current (Figure 9, solid lines). In the case of MUA, the amplitude of the amide I band of adsorbed $\mathrm{Cc}$ is $10^{-2}$, and the surface coverage is 17 $\mathrm{pmol} / \mathrm{cm}^{2}$. However, the amide I band is $7 \times 10^{-3}$ when $\mathrm{Cc}$ is bound to $\mathrm{CcO}$ with a surface coverage of $5 \mathrm{pmol} / \mathrm{cm}^{2}$. Second, the adsorption of $\mathrm{Cc}$ on carboxy-terminated surface is complete within 30 min while that on $\mathrm{CcO}$ takes much longer (>90 min). The latter reveals biphasic adsorption behavior with a plateau reached after $\sim 30 \mathrm{~min}$ and a second increase thereafter (Figure $3 \mathrm{c}$ ). In contrast, the adsorption of $\mathrm{Cc}$ to a carboxy-terminated surface is monotonic across the entire adsorption process. ${ }^{6}$

The ionic strength dependence of $\mathrm{Cc}$ desorption is also disparate for MUA and CcO. On the carboxy-terminated MUA

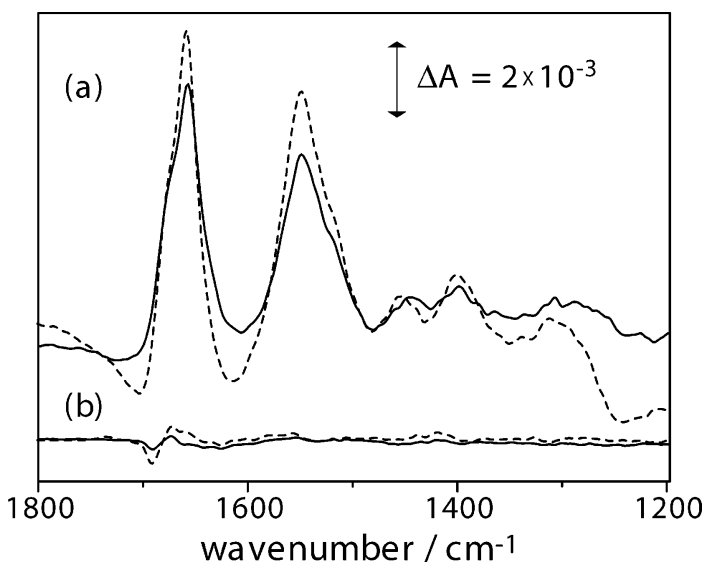

Figure 9. Quantitative surface-enhanced IR spectroscopy of cytochrome c. (a) Absorption spectrum of cytochrome $\mathrm{c}$ bound to the solidsupported cytochrome c oxidase monolayer (continuous trace) and to mercaptoundecanate (dashed trace). (b) Corresponding redox-induced difference spectra of cytochrome c.

$\mathrm{SAM}$, the maximum surface coverage of $\mathrm{Cc}$ is reached at $<10$ $\mathrm{mM} \mathrm{KCl}$ and gradually decreases as the ionic strength is increased. About $80 \%$ of the monolayer coverage is desorbed already at $80 \mathrm{mM} \mathrm{KCl}$ and completely desorbed in the presence of $1 \mathrm{M} \mathrm{KCl} .{ }^{39}$ When $\mathrm{Cc}$ is complexed with $\mathrm{CcO}$, only $50 \%$ of $\mathrm{Cc}$ is detached from $\mathrm{CcO}$ upon increasing the $\mathrm{KCl}$ concentration to $300 \mathrm{mM}$ (Figure 4). However, electron transfer from $\mathrm{Cc}$ to $\mathrm{CcO}$ is completely suppressed at this high ionic strength. ${ }^{15}$ This can be explained by the presence of a population of $\mathrm{Cc}$ that is adsorbed on the $\mathrm{CcO}$ surface but does not participate in electron transfer. The existence of an inactive binding site for $\mathrm{Cc}$ on $\mathrm{CcO}$ has long been proposed ${ }^{40-42}$ based on the multiphasic oxidation kinetics of $\mathrm{Cc}$ on $\mathrm{CcO}$. For the explanation of this behavior, the regulatory site mechanism has been introduced, which envisages a single catalytic site per heme $a_{3}$. Adjacent to the catalytic site is at least one regulatory site where $\mathrm{Cc}$ binds without transferring electrons. Cc bound to the regulatory site weakens binding of $\mathrm{Cc}$ at the catalytic site, thereby reducing the affinity of the enzyme for both substrate and product. The model explains the appearance of a low-affinity/high-velocity second phase at high $\mathrm{Cc}$ concentration as well as the ionic strength dependence of the overall reaction, provided that product dissociation is rate-limiting. ${ }^{21}$

The fraction of the active and the nonactive $\mathrm{Cc}$ population adsorbed on $\mathrm{CcO}$ can be quantitatively determined from the analysis of the band intensities in the SEIRA and SEIDA spectra. The band intensity in the absolute IR spectum (Figure 9a) represents the total amount of surface-bound $\mathrm{Cc}$, i.e., active and nonactive. However, the band intensity in the potential-induced IR difference spectrum (Figure 9b) reflects the amount of bound $\mathrm{Cc}$ participating in the electron-transfer reaction to $\mathrm{CcO}$. In the case of $\mathrm{Cc}$ adsorbed on the MUA surface, the surface coverage of redox-active $\mathrm{Cc}$ is $17 \mathrm{pmol} / \mathrm{cm}^{2}$ as derived from the redox current in the cyclic voltammogram (Figure S2 of the Supporting Information). This value is very close to full monolayer coverage of $\mathrm{Cc}\left(15 \mathrm{pmol} \mathrm{cm}^{-2}\right)$ calculated from the diameter of Cc. ${ }^{43}$ This suggests that all adsorbed $\mathrm{Cc}$ molecules are undergoing electron transfer to the MUA modified electrode. Thus, the ratio of the band intensities of the absolute and the potential-induced IR difference spectra of $\mathrm{Cc}$ on MUA can be used as a reference for $100 \%$ electron-transfer efficiency. The number of molecules that undergo electron transfer $\left(n_{\mathrm{ET}}\right)$ is derived from the absorbance change of the redox-induced IR difference spectrum (Figure 9b). The difference in amplitude of the negative band at $1692 \mathrm{~cm}^{-1}$ and the positive band at $1676 \mathrm{~cm}^{-1}\left(\Delta A_{\left(1676-1692 \mathrm{~cm}^{-}\right.}\right.$ 
1) ) is used and normalized to the number of adsorbed cytochrome c molecules $\left(n_{\mathrm{ads}}\right)$ by recording the absorbance of the amide I band at $1658 \mathrm{~cm}^{-1}$ (Figure 9a)

$$
\frac{n_{\mathrm{ET}}}{n_{\mathrm{ads}}}=100 \times \frac{\Delta A_{\left(1676-1692 \mathrm{~cm}^{-1}\right)}}{A_{\left(1658 \mathrm{~cm}^{-1}\right)}}
$$

The ratio of the IR signals is determined to be $9.7 \%$ for $\mathrm{Cc}$ adhered to the carboxy-terminated SAM (MUA). The same calculation for the bands of $\mathrm{Cc}$ when bound to the solidsupported SAM of CcO yields a ratio of 5.2\%. Taking the redox reaction of $\mathrm{Cc}$ adsorbed to MUA as the reference for $100 \%$ electron transfer (vide supra), only about half $(53 \%)$ of the adsorbed $\mathrm{Cc}$ is involved in electron transfer to $\mathrm{CcO}$, leaving the other half $(47 \%)$ inactive for electron transfer. Thus, the ratio of ET active (or catalytic) Cc and inactive Cc molecules is about $1: 1$. We would like to point out that the electrochemical IR data provide the first direct evidence for the existence of an inactive $\mathrm{Cc}$ population in this heterogeneous ET system. Although such inactive but regulatory species may be present in many bioenergetic systems, they are inherently difficult to detect with conventional electrochemical techniques.

It is reasonable to conclude that the inactive $\mathrm{Cc}$ population is adsorbed to the regulatory site of $\mathrm{CcO}$ as suggested by the controlled binding model for the interaction between cytochrome c and cytochrome oxidase. ${ }^{42}$ The spatial location of the regulatory site is still controversial. Speck et al. ${ }^{42}$ suggested that binding of $\mathrm{Cc}$ either to the phospholipid layer or to a protein site close to the catalytic site influences the binding of (redoxactive) $\mathrm{Cc}$ at the catalytic site, leading to the observed multiphasic kinetics. However, it is obvious from our experiments on the orientational dependence (Figures $3 a$ and $3 b$ ) that $\mathrm{Cc}$ adsorbs to $\mathrm{CcO}$ only when the dedicated binding site on the $\mathrm{P}$-side is exposed. Neither the lipid layer nor the extramembrane surface on the $\mathrm{N}$-side bind $\mathrm{Cc}$. Thus, it is straightforward to conclude that the regulatory site must be on the same protein surface as the catalytic binding site for Cc. Since it has been shown that the chemical nature of the lipid influences the catalytic activity, the lipid layer must interact indirectly with the $\mathrm{Cc} / \mathrm{CcO}$ complex. It is evident that further surface-enhanced IR experiments, including the dependence on Cc concentration, ionic strength, and $\mathrm{pH}$, are required to elucidate the role of the bound but nonproductive $\mathrm{Cc}$ population. Such studies are currently underway.

\section{Conclusions}

In this work, we have addressed the functionality of a lipidreconstituted $\mathrm{CcO}$ monolayer that has been specifically bound via His-tags to a Ni-NTA-modified gold electrode. Full control of the orientation has been achieved by adsorbing the membrane protein via an engineered His-tag into either the $\mathrm{P}$ - or the $\mathrm{N}$-side of the membrane surface. It is demonstrated that only with $\mathrm{CcO}$ orientated to expose the binding site of $\mathrm{Cc}$ to the aqueous bulk solution, reduction of dioxygen is achieved as monitored by a catalytic current. Thus, proper orientation of the membrane protein is mandatory for the physiological reaction to take place, i.e., binding of $\mathrm{Cc}$ and electron transfer to $\mathrm{CcO}$, which then catalyzes the formation of water from dioxygen.

SEIRA spectroscopy has been employed to monitor each of the surface modification steps. The potential-induced IR difference spectrum of $\mathrm{Cc}$ when adsorbed to the solid-supported $\mathrm{CcO}$ film is very similar to the difference spectrum of $\mathrm{Cc}$ when adsorbed to a carboxy-terminated SAM. This implies that the former bears structural and electrostatic similarity to the latter.
Indeed, the terminal carboxylates of aspartyl and glutamyl side chains of $\mathrm{CcO}$ have been found crucial for binding of Cc. ${ }^{14,17,35}$ Quantitative surface-enhanced IR spectroscopy determined a bound but redox-inactive Cc population. As proposed earlier, ${ }^{42}$ these nonproductive $\mathrm{Cc}$ molecules are most probably involved in the regulation of the physiological electron transfer from the catalytically active $\mathrm{Cc}$ population to $\mathrm{CcO}$. The orientational dependence of $\mathrm{Cc}$ binding provided evidence that the nonproductive population is exclusively bound to the same membrane side of $\mathrm{CcO}$ (P-side) as the redox-active population of $\mathrm{Cc}$.

The presented methodology is a general approach as the introduction of affinity tags is routine with modern genetic techniques. Thus, orientational control can be conveniently achieved. An oriented sample is crucial when the vectorial function of a membrane protein is addressed. Many membrane proteins are asymmetric in their functionality as they translocate ions or solutes preferably in one direction or as their stimulus operates only from one side. For instance, the application of a potential difference across the lipid bilayer embedded membrane protein drives the flow of ions in voltage-gated channels. ${ }^{44}$ Such studies are now feasible and may contribute to the elucidation of the molecular mechanisms of this neurologically relevant class of proteins. Moreover, the presented methodology is particularly helpful for high-resolution imaging studies (electron and scanning probe microscopy) where a well-oriented sample is often critical for data interpretation. We have applied scanning probe microscopy and provided direct evidence for the molecular architecture of surface-tethered and membrane-embedded $\mathrm{CcO} .{ }^{24}$

Overall, the presented methodology opens an avenue to study protein-protein interaction on the molecular level. It is certainly most suited to membrane proteins. As we have demonstrated, the interaction of a membrane protein with its native binding partner (here $\mathrm{Cc}$ with $\mathrm{CcO}$ ) can be followed on the atomic level by surface-enhanced IR spectroscopy. We consider this approach to be directly applicable to G-proteins interacting with their cognate receptors (so-called GPCRs) to provide detailed insight into the conformational changes associated with signaling.

Acknowledgment. We acknowledge Professor G. Büldt for continuous generous support. We thank Professors P. Brzezinski (Sockholm) and R. B. Gennis (Urbana-Champaign) for providing the strain of $R$. sphaeroides $\mathrm{CcO}$ with the His-tags on subunits I and II, respectively. This work has been supported by a grant from the Volkswagen foundation ("Intra- und Intermolekulare Elektronenübertragung").

Supporting Information Available: Potential-induced IR difference spectroscopy of the $\mathrm{CcO}$ film electrode and cyclic voltammography of $\mathrm{Cc}$ bound to MUA. This material is available free of charge via the Internet at http://pubs.acs.org.

\section{References and Notes}

(1) Willner, I.; Katz, E. Angew. Chem., Int. Ed. 2000, 39, 1180-1218. (2) Liley, M.; Keller, T. A.; Duschl, C.; Vogel, H. Langmuir 1997, 13, 4190-4192.

(3) Rigler, P.; Ulrich, W. P.; Hoffmann, P.; Mayer, M.; Vogel, H. ChemPhysChem 2003, 4, 268-275.

(4) Schmid, E. L.; Keller, T. A.; Dienes, Z.; Vogel, H. Anal. Chem. 1997, 69, 1979-1985.

(5) Sigal, G. B.; Bamdad, C.; Barberis, A.; Strominger, J.; Whitesides, G. M. Anal. Chem. 1996, 68, 490-497.

(6) Ataka, K.; Giess, F.; Knoll, W.; Naumann, R.; Haber-Pohlmeier, S.; Richter, B.; Heberle, J. J. Am. Chem. Soc. 2004, 126, 16199-16206. (7) Giess, F.; Friedrich, M.; Heberle, J.; Naumann, R.; Knoll, W. Biophys. J. 2004, 87, 3213-3220.

(8) Ataka, K.; Heberle, J. J. Am. Chem. Soc. 2003, 125, 4986-4987.

(9) Burgess, J. D.; Rhoten, M. C.; Hawkridge, F. M. Langmuir 1998 $14,2467-2475$ 
(10) Haas, A. S.; Pilloud, D. L.; Reddy, K. S.; Babcock, G. T.; Moser, C. C.; Blasie, J. K.; Dutton, P. L. J. Phys. Chem. B 2001, 105, 1135111362

(11) Rhoten, M. C.; Burgess, J. D.; Hawkridge, F. M. J. Electroanal. Chem. 2002, 534, 143-150.

(12) Armstrong, F. A. Curr. Opin. Chem. Biol. 2005, 9, 110-117.

(13) Wikström, M. K.; Saari, H. T. Biochim. Biophys. Acta 1977, 462, $347-361$.

(14) Zhen, Y. J.; Hoganson, C. W.; Babcock, G. T.; Ferguson-Miller, S. J. Biol. Chem. 1999, 274, 38032-38041.

(15) Wang, K. F.; Geren, L.; Zhen, Y. J.; Ma, L.; Ferguson-Miller, S.; Durham, B.; Millett, F. Biochemistry 2002, 41, 2298-2304.

(16) Wang, K. F.; Zhen, Y. J.; Sadoski, R.; Grinnell, S.; Geren, L.; Ferguson-Miller, S.; Durham, B.; Millett, F. J. Biol. Chem. 1999, 274, 38042-38050.

(17) Maneg, O.; Malatesta, F.; Ludwig, B.; Drosou, V. Biochim. Biophys. Acta 2004, 1655, 274-281.

(18) Nyquist, R. M.; Heitbrink, D.; Bolwien, C.; Gennis, R. B.; Heberle, J. Proc. Natl. Acad. Sci. U.S.A. 2003, 100, 8715-8720.

(19) Krimm, S.; Bandekar, J. Adv. Protein Chem. 1986, 38, 181-364.

(20) Johnson, E.; Aroca, R. J. Phys. Chem. 1995, 99, 9325-9330.

(21) Michel, B.; Bosshard, H. R. Biochemistry 1989, 28, 244-252.

(22) Miyake, H.; Ye, S.; Osawa, M. Electrochem. Commun. 2002, 4, 973-977.

(23) Svensson-Ek, M.; Abramson, J.; Larsson, G.; Tornroth, S.; Brzezinski, P.; Iwata, S. J. Mol. Biol. 2002, 321, 329-339.

(24) Mayer, D.; Ataka, K.; Heberle, J.; Offenhausser, A. Langmuir 2005, $21,8580-8583$

(25) Ataka, K.; Heberle, J. J. Am. Chem. Soc. 2004, 126, 9445-9457.

(26) Bagus, P. S.; Pacchioni, G. Electrochim. Acta 1991, 36, 16591667.

(27) Li, J. H.; Cheng, G. J.; Dong, S. J. J. Electroanal. Chem. 1996, 416, 97-104.
(28) Salamon, Z.; Hazzard, J. T.; Tollin, G. Proc. Natl. Acad. Sci. U.S.A 1993, 90, 6420-6423.

(29) Burgess, J. D.; Jones, V. W.; Porter, M. D.; Rhoten, M. C.; Hawkridge, F. M. Langmuir 1998, 14, 6628-6631.

(30) Friedrich, M. G.; Giess, F.; Naumann, R.; Knoll, W.; Ataka, K.; Heberle, J.; Hrabakova, J.; Murgida, D. H.; Hildebrandt, P. Chem. Commun. 2004, 2376-2377.

(31) Dutton, P. L.; Wilson, D. F.; Lee, C. P. Biochemistry 1970, 9 , 5077-5082

(32) Roberts, V. A.; Pique, M. E. J. Biol. Chem. 1999, 274, 3805138060

(33) Millett, F.; Darleyusmar, V.; Capaldi, R. A. Biochemistry 1982, 21, 3857-3862.

(34) Millett, F.; de Jong, C.; Paulson, L.; Capaldi, R. A. Biochemistry 1983, 22, 546-552.

(35) Drosou, V.; Malatesta, F.; Ludwig, B. Eur. J. Biochem. 2002, 269, 2980-2988.

(36) Koppenol, W. H.; Margoliash, E. J. Biol. Chem. 1982, 257, 44264437.

(37) Rieder, R.; Bosshard, H. R. J. Biol. Chem. 1980, 255, 4732-4739.

(38) Smith, H. T.; Staudenmayer, N.; Millett, F. Biochemistry 1977, 16 , 4971-4974.

(39) Clark, R. A.; Bowden, E. F. Langmuir 1997, 13, 559-565.

(40) Garber, E. A. E.; Margoliash, E. Biochim. Biophys. Acta 1990, 1015, 279-287.

(41) Ferguson-Miller, S.; Brautigan, D. L.; Margoliash, E. J. Biol. Chem. 1976, 251, 1104-1115.

(42) Speck, S. H.; Dye, D.; Margoliash, E. Proc. Natl. Acad. Sci. U.S.A. 1984, 81, 347-351.

(43) Fedurco, M. Coord. Chem. Rev. 2000, 209, 263-331.

(44) MacKinnon, R. FEBS Lett. 2003, 555, 62-65. 